\title{
Length of productive life of crossbred sows is affected by farm management, leg conformation, sow's own prolificacy, sow's origin parity and genetics
}

\author{
T. Serenius ${ }^{\dagger}$ and K. J. Stalder \\ lowa State University, Department of Animal Science, Ames, IA 50011, USA
}

(Received 28 July 2006; Accepted 2 January 2007)

\begin{abstract}
The purpose of the current study was to determine if the parity of the litter in which a female was born and the number of pigs within that same litter are associated with future length of productive life (LPL). An additional objective of the study was to examine the associations of leg conformation (evaluated at approx. $100 \mathrm{~kg}$ of live weight), age at first farrowing, litter size at first farrowing, and age and backfat thickness at $100 \mathrm{~kg}$ on LPL in the Finnish crossbred (Landrace $\times$ Large White or Large White $\times$ Landrace) population. The data analysed contained information on 11761 sows, and proportional hazard model (Weibull) was fitted on the data using the Survival Kit. Log likelihood tests were utilised to determine if the individual effects have a significant impact on LPL. Farm conditions and management were identified as major factors impacting on LPL (P < 0.001). Other factors significantly $(\mathrm{P}<0.001)$ associated with LPL were leg soundness score, age at first farrowing, and litter size at first farrowing. The better the leg score, the younger age at first farrowing, and the larger litter at first farrowing, the longer sows tended to remain in the herd from the present. Although sows born in litters first, second, and sixth parities had slightly greater risk of being culled when compared with sows born in litters from the other parities, the effect was not statistically significant. Sufficient genetic variation exists in the population evaluated in this study for LPL $\left(\mathrm{h}^{2}=0.25\right)$, such that it will be possible to improve LPL through traditional selection methods in an efficient breeding programme. Thus, there are many factors which impact on LPL, and possibilities to improve all of them should be considered in order to improve the economics and animal welfare of modern pork production operations.
\end{abstract}

Keywords: parity, pigs, productive life, survival analysis

\section{Introduction}

Length of productive life (LPL) plays both an economic and animal welfare role in many pork production systems throughout the world (Serenius, 2004; Stalder et al., 2004). Thus, knowledge concerning factors that impact upon LPL is needed in order to improve LPL by changing management, mating systems, and/or breeding practices.

Previous literature has reported that sows with good leg conformation tend to remain in the herd longer when compared with sows having poor leg conformation (Yazdi et al., 2000a; Serenius and Stalder, 2004). Similarly, litter size and age at first farrowing have been shown to be favourably associated with LPL (Tholen et al., 1996b; Yazdi et al., 2000b; Serenius and Stalder, 2004). In other words, the larger the litter size

\footnotetext{
${ }^{\dagger}$ Present address: MTT Agrifood Research Finland, Biotechnology and Food Research, 31600 Jokioinen, Finland.

E-mail: timo.serenius@mtt.fi
}

and lower age at first farrowing, the greater LPL has been in previously reported studies. On the contrary, litter size appeared not to be associated with LPL when culling for poor reproductive performance was not permitted in the Maternal Line National Genetic Evaluation Program study by the US National Pork Producers Council (NPPC) (Serenius et al., 2006b).

No clear consensus exists in the scientific literature regarding the association between LPL and other economically important production traits (daily gain, feed conversion ratio) and carcass composition (lean meat content and backfat thickness) traits. For example, Lopez-Serrano et al. (2000) found both average daily gain and backfat thickness were unfavourably genetically correlated with sow stayability (a measure of length of productive life or lifetime productivity). However, the associations were not as clear in a study reported by Yazdi et al. (2000b). Moreover, our earlier results have shown associations to be population dependent (Serenius and Stalder, 2004; Serenius et al., 
2006b). Previous studies have concentrated on different aspects of LPL and have been based on purebred populations, whereas most of the sows in commercial pork production are crossbred sows. Thus, in order to optimise management practices for crossbred populations, the associations should be estimated from crossbred populations. Additionally, production information from crossbred animals along with information from their purebred ancestors should be utilised to develop more accurate breeding values for longevity and other production traits where the performance of the crossbred animal is included in the breeding objectives.

The parity of the litter in which a female was born appears to impact her future performance. For example, Tummaruk et al. (2001) found that sows originating from gilt litters had significantly longer wean-to-oestrus intervals when compared with sows born in fourth and fifth parity litters. Thus, the question arises whether crossbred sows used to in commercial piglet production systems should be selected from dams in their later parities? Similarly, it is not clear whether litter size in which a female was born impacts a sow's future LPL. The purpose of current study was to determine if the parity of the litter in which a female was born and the number of pigs within that same litter are associated with future LPL. An additional objective of the study was to examine the associations of leg conformation, age at first farrowing, litter size at first farrowing, and age and backfat thickness at $100 \mathrm{~kg}$ on LPL in the Finnish crossbred (Landrace $\times$ Large White or Large White $\times$ Landrace) population. Moreover, the additive genetic sire effect was included in the statistical model, so the relationship among animals was accounted for, and thus, heritability estimate for LPL was also estimated.

\section{Material and methods}

Data

Data from the Finnish litter recording and on-farm testing schemes were combined to evaluate the associations between age and backfat thickness at $100 \mathrm{~kg}$ live weight, parity of the litter in which a female was born, the number of pigs within that same litter (number weaned), age at first farrowing, litter size at first farrowing (number born alive) and leg conformation (leg soundness score) with sows' LPL (Table 1). LPL was defined as time (days) from first farrowing to culling and/or mortality or censoring (sow was still alive at the time of evaluation). Breeding advisors from FABA Breeding (Finnish Animal Breeding Association) scored all sows for leg soundness using a scale from one to five ( $1=$ worst and $5=$ best) as described by Serenius et al. (2001). Because of a low number of observations in classes one and five, class one records were combined with class two, and similarly class five records were combined with class four. Thus, a three-category soundness scoring system $(1-2,3,4-5)$ was utilised in the current analysis. Backfat thickness was determined as an average
Table 1 Means, standard deviations (s.d.), minima (Min) and maxima (Max) of parity of the litter in which a sow was born, size of the litter in which a sow was born (LSorig), number of piglets born alive at first farrowing (NBA), age at first farrowing (AFF), backfat thickness at $100 \mathrm{~kg}$ live weight $(B F 100, \mathrm{~mm})$, age at $100 \mathrm{~kg}$ live weight (Age100), leg soundness score (Leg score), and length of productive life $(L P L)$ in the Finnish crossbred sow population

\begin{tabular}{|c|c|c|c|c|}
\hline & Mean & s.d. & Min & Max \\
\hline Origin parity & 3.01 & 1.90 & 1 & 8 \\
\hline LSorig & 10.2 & 2.13 & 5 & 15 \\
\hline NBA & 10.1 & 2.58 & 5 & 15 \\
\hline AFF & 351.8 & 40.7 & 260 & 700 \\
\hline $\mathrm{BF} 100(\mathrm{~mm})^{\dagger}$ & 9.9 & 1.7 & 4.3 & 20.7 \\
\hline Age100 & 163.1 & 15.1 & 116 & 265 \\
\hline $\begin{array}{l}\text { Leg score } \\
\text { LPL }^{\S}\end{array}$ & 3.57 & 0.52 & 2 & 4 \\
\hline Uncensored & 536.3 & 429.3 & 1 & 2807 \\
\hline Censored & 527.0 & 353.1 & 5 & 3083 \\
\hline
\end{tabular}

${ }^{\dagger}$ Backfat was measured as an average of three ultrasound measures at approximately last rib.

${ }^{\ddagger}$ Scored by Finnish Animal Breeding Association breeding advisers: 2 = worst; $4=$ best.

${ }^{\S} \mathrm{LPL}$ : time from first farrowing to culling or censoring.

of three ultrasound measures taken at approximately the last rib. Age and backfat thickness were adjusted to a constant weight $(100 \mathrm{~kg})$ as suggested by National Swine Improvement Federation (1996).

To avoid problems in statistical analysis due to small contemporary groups, records were utilised only from the farms having at least 10 gilt (parity 1) farrowings annually. Similarly, records were excluded if performance traits were not within the following range of values (litter size traits: 1 to 20; age at first farrowing: 260 to 700 days) or if information the parity in which a female was born or the litter size in which a female was born was missing. The data analysed contained information from 11761 sows, and they were daughters of 1590 boars. Approximately onethird $(31 \%)$ of LPL observations were censored. The mean censoring age was 527 days, and similarly the mean culling age was 536 days. Phenotypic levels of the traits included in the statistical model are presented in Table 1. After all the pedigrees were traced back to founder animals, there were 2723 animals in the pedigree.

\section{Statistical analysis}

Survival analysis is considered as a well accepted method in the evaluation of longevity or similar traits in several species. It is widely utilised in the analysis of LPL particularly dairy cattle (Ducrocq, 2006). When utilising survival analysis, the risk of culling or death at any given time point is evaluated using a proportional hazard models. The baseline hazard is most commonly assumed to follow a Weibull distribution (Damgaard, 2006; Ducrocq, 2006; Serenius and Stalder, 2006). Moreover, the effects defined in a statistical model are often presented with a hazard rate, 
which indicates proportional risk of animal being culled at any given time point $(t)$.

In the current study, statistical analyses were based on survival analysis. The proportional hazard model following a Weibull distribution was applied to the data using the Survival Kit (Ducrocq and Solkner, 2001). The validity of Weibull distribution was assessed by plotting $\log (-\log (S(t)))$ against $\log (t)$, where $S(t)$ is Kaplan-Meier survivor function and $t$ is time (days) from first farrowing (Figure 1). As the plot of this relationship displayed approximately a straight line, the Weibull distribution was assumed to fit the data appropriately. Moreover, the separate lines for the other possible strata variables used in the present study (leg score, litter size in which the female was born, parity of the litter in which the female was born) were roughly parallel (data not shown), and thus, only one baseline hazard was utilised in the present analyses. The hazard function of sow's LPL at $t$ days after first farrowing is written as:

$$
h(t)=\lambda \rho(\lambda t)^{\rho-1} e^{X(t)^{\prime} b},
$$

where $\lambda \rho(\lambda t)^{\rho-1}$ is the Weibull baseline hazard function with location $(\lambda)$ and shape $(\rho)$ parameters, $b$ is a vector of fixed and random effects, and $X(t)$ is corresponding incidence matrix. Time independent fixed effects included in $b$ were the parity of the litter in which a sow was born $(1,2, \ldots, 7, \geq 8)$, number of piglets weaned from the litter in which the female was born $(\leq 5,6, \ldots, 14, \geq 15)$, leg soundness score $(1-2,3,4-5)$, and number of piglets born alive at first farrowing $(\leq 5,6, \ldots, 14, \geq 15)$. Similarly, linear regressions of age and backfat thickness at $100 \mathrm{~kg}$ live weight, linear and quadratic regressions of age at first farrowing, time dependent farm-year interaction, and random genetic sire were also included in $b$. The random genetic sire was assumed to have zero mean and $\operatorname{var}($ sire $)=A \sigma_{s}^{2}$, where $\sigma_{s}^{2}$ is the sire variance, and $A$ is the additive relationship matrix among the sires. The heritability $\left(h^{2}\right)$ of LPL was calculated as showed by

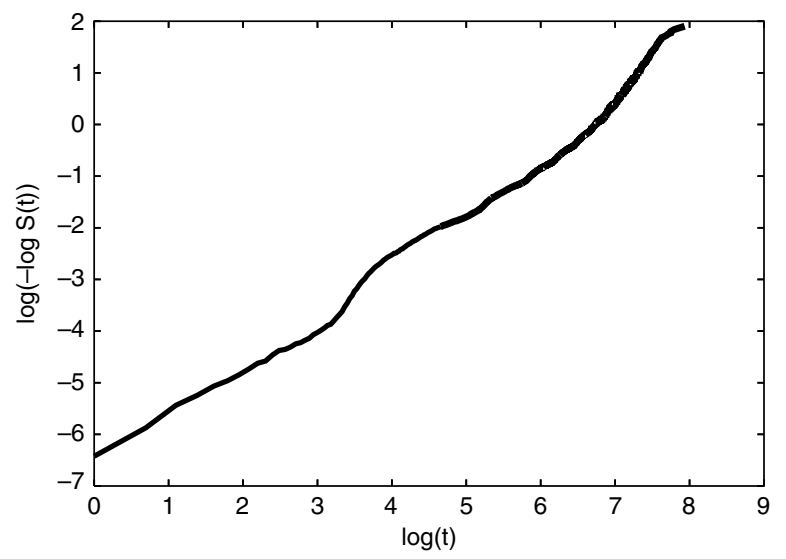

Figure 1 Graphical test for validity of Weibull distribution on current dataset: Survivor function $(\log (-\log S(t)))$ plotted against natural logarithm of time (days) from first farrowing $(\log (t))$. A straight line indicates Weibull fitting well on the data.
Ducrocq and Casella (1996): $h^{2}=4 \sigma_{s}^{2} /\left(\pi^{2} / 6+\sigma_{s}^{2}\right)$, where $\pi^{2} / 6$ is the variance of extreme value distribution.

\section{Results}

The results of log-likelihood test are presented in Table 2 . The $P$-values and measures of proportion of variation explained by model $\left(R^{2}\right)$ that are presented are based on log likelihood differences when one effect at a time was excluded from the full model. In addition to the effects in Table 2, clear variation due to additive genetic sire effects $\left(h^{2}=0.25\right)$ was observed from the present Finnish pig population evaluated.

Time dependent effect of farm-year interaction clearly had the greatest effect on LPL in the current study (Table 2). For example, the $R^{2}$ in the full model was 0.29 , and when the effect of farm-year interaction is excluded from the model, the corresponding $R^{2}$ was reduced to only 0.05 . Additionally, leg soundness score explained a significant $(P<0.001)$ proportion of variation in a sow's risk of being culled or conversely the sows' LPL (Table 2). From the present study, sows having soundness scores lower than 3 appear to have a relatively higher risk of being culled when compared with sows with superior soundness scores (Figure 2). The difference in risk of being culled between soundness scores 3 and 4 was clearly smaller in the present study.

The effect of age at first farrowing on the risk of being culled in the present study was also highly significant $(P<0.001)$ (Table 2). The greater age at first farrowing, the greater the risk of a sow being culled (Figure 3). According to the current results, the relationship between age at first farrowing and the sows' risk of being culled appears to be non-linear. This is because the quadratic effect was also highly significant $(P<0.001)$. However, the slope of the quadratic portion of the regression line is relatively smooth with the linear portion (Figure 3), and hence, the non-linearity of the affect is not dramatic.

From the present findings, the log likelihood test indicated that age at $100 \mathrm{~kg}$ live weight may be associated

Table $2 P$ values and reliabilities $\left(R^{2}\right)$ from log likelihood ratio test when the covariates were tested by excluding one at a time (last) from the full model ${ }^{\dagger}$

\begin{tabular}{lrc}
\hline \hline & $P$ value & $R^{2}$ \\
\hline Farm $\times$ year & $<0.001$ & 0.056 \\
Origin parity & 0.717 & 0.288 \\
LSorig & 0.902 & 0.284 \\
Leg score & $<0.001$ & 0.287 \\
NBA & $<0.001$ & 0.281 \\
AFF & $<0.001$ & 0.286 \\
AFF & $<0.001$ & 0.287 \\
BF100 & 0.395 & 0.288 \\
Age100 & 0.017 & 0.287 \\
\hline \hline
\end{tabular}

${ }^{\dagger}$ For abbreviations, see Table 1. 


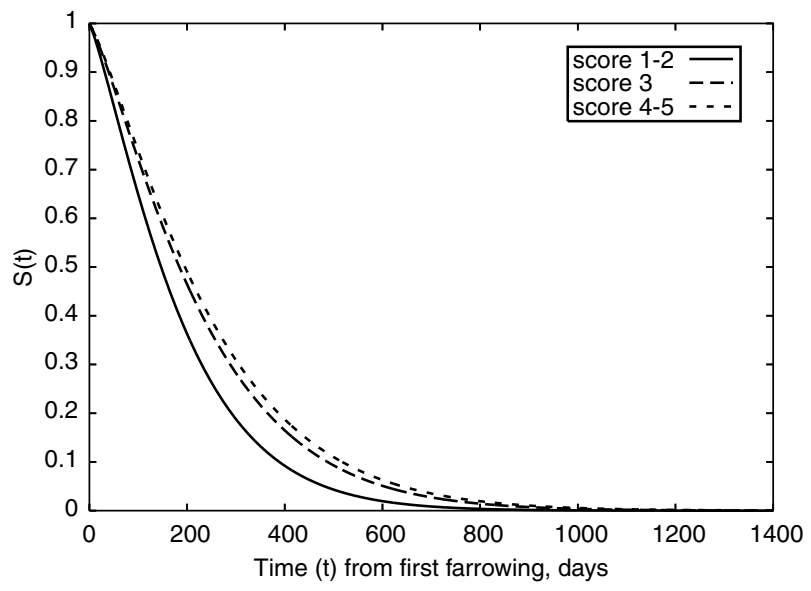

Figure 2 Estimated survivor functions $(S(t))$ for different leg soundness scores. Scoring is from 1 (worst) to 5 (best). Length of productive life is determined as a time from first farrowing to culling or censoring.

$(P<0.05)$ with sows' risk of being culled (Table 2$)$ but the association is not strong (Figure 3). The effect of backfat thickness at $100 \mathrm{~kg}$ live weight was not significant $(P=0.40)$ in the present analysis.

In the current data, sows from parity 1 and 2 as well as the sixth parity had a greater risk of being culled when compared with sows from the other five parity classes (Figure 4). However, the effect was not statistically significant (Table 2). Similarly, the effect of litter size in which the sow was born was not significantly associated with LPL. However, the effect of sow's own record of litter size at first farrowing was highly associated with LPL $(P<0.001)$ (Table 2). Sows having fewer than nine piglets born alive have a greater risk of being culled than the sows that farrowed litters with greater than nine piglets born alive (Figure 4).

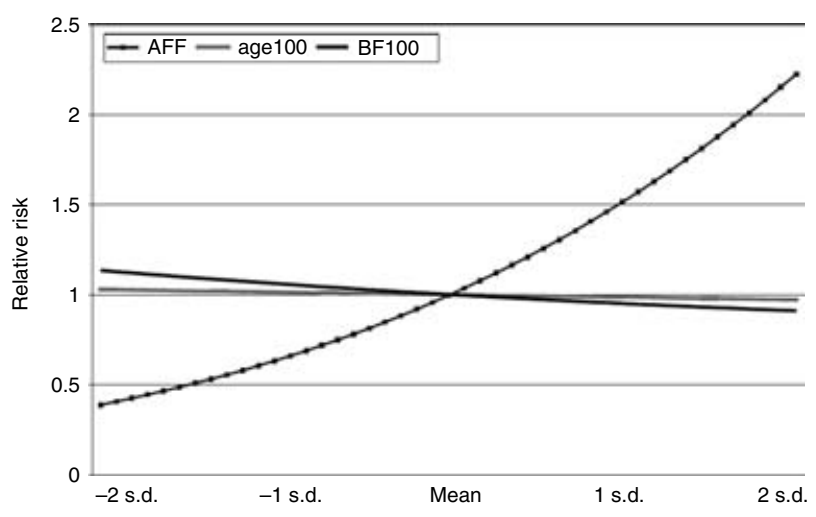

Figure 3 Estimated regression effects of age at first farrowing (AFF), age at $100 \mathrm{~kg}$ live weight (age100), and backfat thickness at $100 \mathrm{~kg}$ live weight (an average of three ultrasound measures at approx. last rib; BF100) on sows' relative risk of being culled at any given time point. Covariates have been scaled to population mean and s.d. (see Table 1) in order to compare their relative importance.

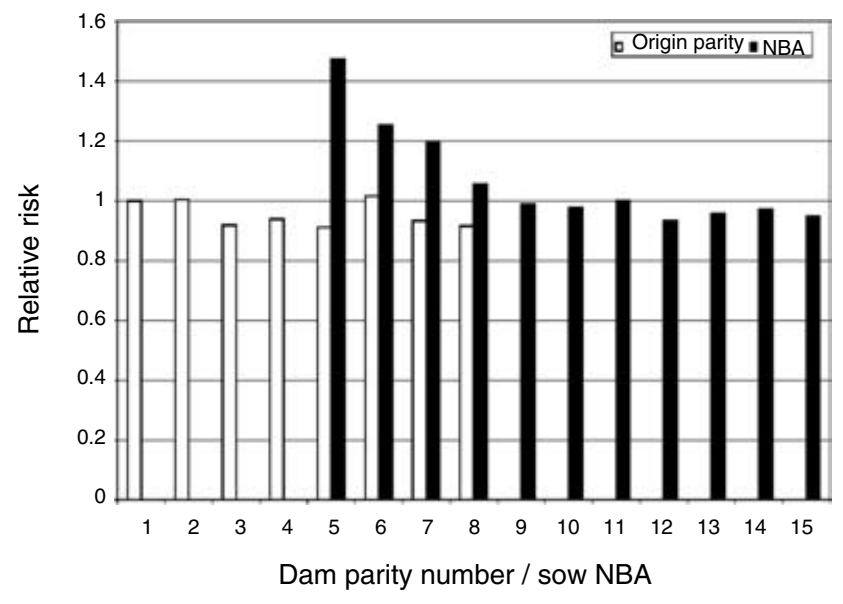

Figure 4 Estimated effects of the parity of the litter in which a female was born and the number of pigs within that same litter (number born alive, NBA) at first farrowing on relative risk of sow being culled at any given time point (from first farrowing to culling). The risk of culling is scaled relatively to class 1 of origin parity and class 11 of NBA.

\section{Discussion}

The objective of current study was to determine if the parity of the litter in which a female was born and the number of pigs within that same litter are associated with future LPL. Moreover, associations between age at first farrowing, as well as age and backfat thickness at $100 \mathrm{~kg}$ on LPL from crossbred females (Landrace $\times$ Large White or Large White $\times$ Landrace) in the Finnish recording scheme were evaluated. Data from Finnish litter recording scheme and on-farm test were combined and evaluated using survival analysis. Thus, the trait analysed was the individual sow's risk of being culled at any given time point. Moreover, an additive genetic sire effect was included in the statistical model and a heritability estimate for sow's LPL was estimated.

Current results indicate that litter size in which the sow was born from her origin parity did not significantly impact on her future LPL. Thus, there should be little or no concern that selecting replacement gilts from large litters would reduce the LPL from the Finnish population evaluated. Although the effect of the parity of the litter in which a sow was born did not statistically impact the sows' $L P L$, there was a tendency that sows from parity 1, 2, and 6 have a greater risk of being culled when compared with sows born in litters from the other five parity classes. Tummaruk et al. (2001) found sows from gilt litters (parity 1) to have longer weaning-to-oestrus interval when compared with sows born to litters from parities 4 and 5 . Because reproductive failure is the most common reason for involuntary culling (Stalder et al., 2004), their findings are in agreement with the present tendency.

According to the results from the present study, the time-dependent effect of farm and year interaction explains the greatest proportion of variation in LPL. Earlier studies have found significant associations between the farm-year 
interaction and sow longevity (Yazdi et al., 2000b; Serenius and Stalder, 2004). The fact that farm-year environmental effects impact on LPL is readily apparent, as operations have different culling policies and other management practices differ among farms in Finland. Moreover, our impression is that the farm-year effect also explains management and the farms' facility related factors, which contribute to leg- and reproductive problems. This is suggested, because (i) reproductive failure and leg soundness are the most commonly identified reasons for involuntary culling (Stalder et al., 2004), and (ii) the variation in farm conditions and management is relatively large or wide in Finland (Serenius, 2004). Thus, attention should focus on management and the farms' facilities in order to optimise $L P L$, especially if an individual operation is facing poor LPL challenges.

The current results indicate that leg conformation and age at first farrowing are significantly associated with LPL. The better the leg scores and the younger a gilt at first farrowing, the greater the sow's probability of survival to any given time point. These findings are in agreement with earlier studies (Tholen et al., 1996a and b; Lopez-Serrano et al., 2000; Yazdi et al., 2000a and b; Serenius and Stalder, 2004). Our results further indicate that the association between age at first farrowing and LPL is slightly non-linear, the slope increases with increased sow age. In any case, association between age at first farrowing and LPL indicates that sows that reach puberty at an earlier age tend to remain in the herd longer when compared with sows that reach puberty at a later age. This indicates that gilts that reach puberty at an earlier age, and gilts having problems conceiving at their first insemination are likely to have reproductive problems later in life that will ultimately shorten the sow's LPL. If the association is only due to management factors, the current results indicate that management should support gilts to have their first litter as early in life as is reasonably possible. However, in terms of overall sow profitability, it should be remembered that litter size at first farrowing tends to increase with the increase in age at first farrowing or at first mating (Schukken et al., 1994; Tummaruk et al., 2001). We do not suggest breeding immature gilts, but our results support the fact that the optimal age (highest lifetime production) at first conception may be close to 200 to 210 days as supported by Schukken et al. (1994). This range translates to 320 to 330 days of age at first farrowing, which is lower than the average age at first farrowing from the current data set.

Our results indicate that a small number of pigs born at first farrowing has a detrimental impact on LPL. This is in agreement with previous work (Yazdi et al., 2000b; Serenius and Stalder, 2004). However, these results are not supported by our previous work when a different field data set was utilised where no clear association between litter size and LPL was found in a comparison of six different genetic lines, in which culling due to poor reproductive performance had not been practiced (Serenius et al., 2006b).
Thus, the association between litter size and LPL obtained from field data may be the result of autocorrelation, i.e., when sows are culled due to small litters, their LPL is automatically lower than those which are not culled due to small litters - given that all the other effects are held constant.

Age and backfat thickness had a very small effect on the sow's risk of being culled in the current study. The tendency was such that greater backfat thickness and a greater age at $100 \mathrm{~kg}$ live weight were associated with a lower sow culling risk at any time point. The tendency and magnitude of association is supported from our earlier studies based on data from Finnish purebred Landrace population (Serenius and Stalder, 2004). However, the strength of association between backfat thickness and LPL seems to differ between the populations (Serenius and Stalder, 2004; Serenius et al., 2006b). This indicates that optimum management practices, as well as breeding objectives, vary depending on the population evaluated.

An additive genetic component clearly contributed to the variation in LPL observed in this study as indicated by the moderate heritability $\left(h^{2}=0.25\right)$. This is in agreement with previous findings (Yazdi et al., 2000a; Serenius and Stalder, 2004), where heritability estimates of LPL from survival analysis has ranged between 0.10 and 0.31 . Thus, it is possible genetically to improve LPL using traditional selection methods and an efficient breeding programme. However, it should be remembered that realised genetic gain in LPL will depend on many factors in breeding programme. For example, the genetic correlations between LPL and other traits under selection, and the weight of LPL in maternal line index will contribute to the rate of improvement of all traits in the index. Fortunately, there is evidence that leg conformation and age at first farrowing are genetically favourably associated with LPL (Serenius et al., 2006a).

All in all, current results showed that many factors impact on LPL, farm-year interaction being one of the most important ones. Thus, pork operations should focus on all of these factors in order to improve LPL and to obtain the most efficient piglet production for the amount of money invested in each replacement gilt. In other words, producing the same or more pigs at less cost to the operation.

\section{Conclusions}

The current results indicate that farm $\times$ year interaction very clearly affects LPL. Thus, farm conditions and management are the first factors producers should examine if LPL problems exist within a pork operation. The results further indicated that gilts farrowing at an earlier age tended to remain in the herd for a greater amount of time when compared with gilts which farrowed their first litter at an older age. Additionally, first parity litter size was significantly associated with LPL. However, the association between litter size and LPL may be result of autocorrelation due to the culling policies practiced (gilts with small 
litters are culled systematically). The effects of the parity of the litter in which a female was born and the number of pigs within that same litter are not statistically significantly associated with LPL. Lastly, sufficient genetic variation for LPL was observed such that it should be possible to improve LPL through traditional selection methodology in an efficient breeding programme.

\section{Acknowledgements}

This journal paper of the lowa Agriculture and Home Economics Experiment Station, Ames, IA, project no. 3456, was supported by Hatch Act and State of lowa funds. Additional funding and support for the Post-Doc of Timo Serenius was provided by the Academy of Finland (no. 212257).

\section{References}

Damgaard LH 2006. Joint quantitative genetic analysis of survival, linear Gaussian and ordered categorical traits. Proceedings of the eighth world congress on genetics applied to livestock production. Belo Horizonte, Brazil, CD-ROM communication 26-06.

Ducrocq V 2006. Current status and prospects of survival analysis in animal breeding. Proceedings of the eighth world congress on genetics applied to livestock production. Belo Horizonte, Brazil, CD-ROM communication 26-07.

Ducrocq V and Casella G 1996. A Bayesian analysis of mixed survival models. Genetics Selection Evolution 28, 505-529.

Ducrocq V and Solkner J. 2001. The Survival Kit V3.12. User's manual. Available: http://www-sgqa.jouy.inra.fr/diffusions.htm. Accessed 29 June 2006

López-Serrano M, Reinsch N, Looft H and Kalm E 2000. Genetic correlations of growth, backfat thickness and exterior with stayability in large white and landrace sows. Livestock Production Science 64, 121-131.

National Swine Improvement Federation 1996. Guidelines for uniform swine improvement programs. Available: http://www.nsif.com/. Accessed 25 July 2006.

Schukken YH, Buurman J, Huirne RB, Willemse AH, Vernooy JC, van den Broek J and Verheijden JH 1994. Evaluation of optimal age at first conception in gilts from data collected in commercial swine herds. Journal of Animal Science 72, 1387-1392.
Serenius T 2004. Genetics of sow efficiency in the Finnish Landrace and Large White populations. Agrifood Research Reports 55. MTT Agrifood Research Finland, Helsinki, Finland.

Serenius T and Stalder KJ 2004. Genetics of length of productive life and lifetime prolificacy in the Finnish Landrace and Large White pig populations. Journal of Animal Science 82, 3111-3117.

Serenius T and Stalder KJ 2006. Selection for sow longevity. Journal of Animal Science 84, E166-E171.

Serenius T, Sevón-Aimonen ML and Mäntysaari EA 2001. The genetics of leg weakness in Finnish Large White and Landrace populations. Livestock Production Science 69, 101-111.

Serenius T, Stalder KJ and Fernando RL 2006a. Genetic associations of length of productive life with age at first farrowing and leg soundness score in Finnish Landrace population. Proceedings of the eighth world congress on genetics applied to livestock production. Belo Horizonte, Brazil, CD-ROM communication 06-08.

Serenius T, Stalder KJ, Baas TJ, Mabry JW, Goodwin RN, Johnson RK, Robison OW, Tokach M and Miller RK 2006b. National pork producers council maternal line national genetic evaluation program: A comparison of sow longevity and trait associations with sow longevity. Journal of Animal Science 84, 2590-2595.

Stalder KJ, Knauer M, Baas TJ, Rothschild MF and Mabry JW 2004. Sow longevity. Pig News and Information 25, 53N-74N.

Tholen E, Bunter KL, Hermesch S and Graser HU 1996a. The genetic foundation of fitness and reproduction traits in Australian pig populations .1. Genetic parameters for weaning to conception interval, farrowing interval, and stayability. Australian Journal of Agricultural Research 47, 1261-1274.

Tholen E, Bunter KL, Hermesch S and Graser HU 1996b. The genetic foundation of fitness and reproduction traits in Australian pig populations .2. Relationships between weaning to conception interval, farrowing interval, stayability, and other common reproduction and production traits. Australian Journal of Agricultural Research 47, 1275-1290.

Tummaruk P, Lundeheim N, Einarsson S and Dalin AM 2001. Effect of birth litter size, birth parity number, growth rate, backfat thickness and age at first mating of gilts on their reproductive performance as sows. Animal Reproduction Science 66, 225-237.

Yazdi MH, Lundeheim N, Rydhmer L, Ringmar-Cederberg E and Johansson K 2000a. Survival of Swedish Landrace and Yorkshire sows in relation to osteochondrosis: a genetic study. Animal Science 71, 1-9.

Yazdi MH, Rydhmer L, Ringmar-Cederberg $\mathrm{E}$, Lundeheim $\mathrm{N}$ and Johansson $\mathrm{K}$ $2000 \mathrm{~b}$. Genetic study of longevity in Swedish Landrace sows. Livestock Production Science 63, 255-264. 